\section{Cutting-edge technology on offer}

For every dental professional looking to use cutting-edge technologies in order to deliver outstanding care to all their patients, Carestream Dental has a solution.

The CS R4+ practice management system offers an array of features designed to make your everyday life easier. The KPIs enable you to monitor business performance in real-time and then decide for yourself what you'd like to change going forward. The seamless integration with DEPPA also means that all Denplan practices enjoy significant time saving benefits and simpler workflows.

With regards to imaging, Carestream Dental provides a comprehensive portfolio of solutions that caters to the needs of every practice. From the worldwide popular CS 8100 family of imaging units to the CS 3600 intraoral scanner and the CS 7200 imaging plate system, there is something for you.

To find out more about which technologies are ideal, meet the Carestream Dental team on Stand L34 at the BDIA Dental Showcase 2018 event.

For more information, contact Carestream Dental on 0800169 9692 or visit www.carestreamdental.co.uk.

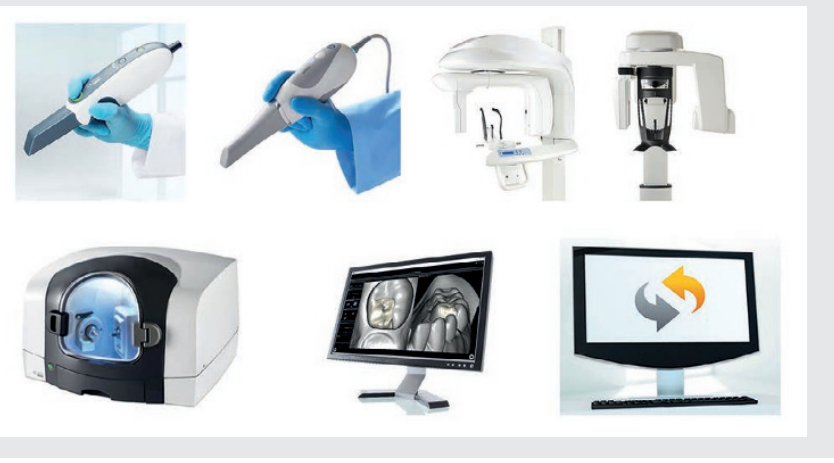

\section{Simplify your patient plan in one easy step}

The Dalai Lama famously said that 'simplicity is extremely important for happiness'. Over time, myriad inventions have made our lives simpler, from the humble wheel to our inter-connected computers, tablets and mobile phones. And the pursuit of a simpler and therefore happier life continues. To help in the fast-paced and increasingly challenging world of dentistry, Patient Plan Direct offers a low-cost, simple, flexible and practice-branded solution to running patient payment plans. So, simply by not paying your plan provider for frills you don't need, your practice life can be transformed.

Simon Reynolds, Commercial Director at Patient Plan Direct, said: 'Our solution to helping practices to run a successful payment plan is low-cost, simple, yet highly effective, incorporating the support, training and tools your practice needs. Do you really need cocktails at flashy exhibition stands, golf days or trips abroad from your plan provider?'

The team at DB Dental agrees, saying: 'We have made significant savings by switching to Patient Plan Direct - a process that was simple and successful. The level of service, support and advice has been outstanding.

To find out more about how to simplify your working life to the benefit of your team and your patients, and how the NEW Bulk Change process can make switching plan provider even easier, visit www.patientplandirect.co.uk/simpleswitch.

\section{Bumblebee charity supported at Showcase}

E K Communications Ltd (EKC) is supporting the Bumblebee Conservation Trust - a charity which aims to ensure that the remaining populations of bees have a long-term future in the UK - at the BDIA Dental Showcase 2018.

EKC is delighted to be supporting the Bumblebee Conservation Trust, in memory of a beloved friend who worked at The Dentist and Dental Update for more than 20 years before losing her battle to cancer in 2012.

Please visit EKC at Stand H10 for your 'Bee' and donate any loose change. Whether it is $1 \mathrm{p}$ or a $£ 1$, the Bumblebee Conservation Trust will put your donations to good use.

Bumblebees are an important and cherished component of our biodiversity. However, in the last 80 years our bumblebee popula-

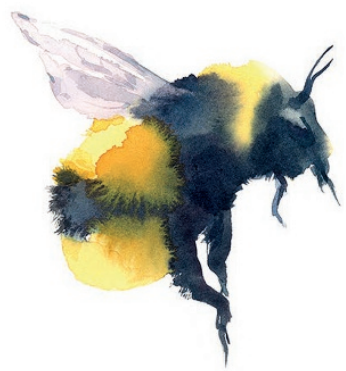
tions have crashed. Two species have become nationally extinct and several others have declined dramatically.

For more information, visit: www.bumblebeeconservation.org or www.ekcommunications.co.uk.

\section{Showcasing the latest water flossing technology}

The very latest in water flossing technology will be on show at the BDIA Dental Showcase 2018 event at Stand H6 from the Waterpik team.

The team will present the Whitening Water Flosser which makes it easy to clean hard to reach areas between the teeth and below the gum line and is proven to help keep teeth white.

The flosser features an improved grip pressure control and handle hose swivel to help patients to remove debris and harmful bacteria that toothbrushes and traditional floss leave behind.

This hi-tech model also has an advanced pressure control system with 10 settings as well as a specially engineered handle that infuses patented whitening technology into the water.

The company is also promoting the Waterpik Whitening Tablets which effectively remove stains and polish away stubborn marks, but are as gentle as regular toothpaste.

To help patients to achieve optimum oral hygiene levels, come and speak to the Waterpik team and delegates can also take part in an exciting interactive theatre experience.

More information is available at www.waterpik.co.uk.
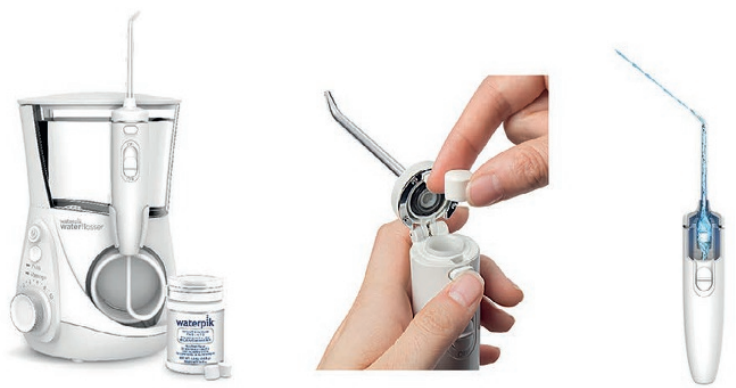